\title{
COMPARTIMENTAÇÃO TOPOSSEQÜENCIAL E CARACTERIZAÇÃO FITOSSOCIOLÓGICA DE UM CAPÃO DE FLORESTA OMBRÓFILA MISTA
}

\author{
Gustavo Ribas Curcio*, Annete Bonnet**, Débora Pestana**, Lígia Souza***, \\ Luís Gustavo Socher****, Franklin Galvão*****, Carlos Vellozo Roderjan***** \\ *Eng. Agrônomo, Dr., Embrapa Florestas - curcio@cnpf.embrapa.br \\ **Bióloga, Dra. - a bonnet@hotmail.com; debora@milenio.com.br \\ ***Eng. Florestal, Doutoranda em Eng. Florestal, UFPR - ligiaengflo@yahoo.com.br \\ ****Eng. Florestal, M.Sc., COPEL - luis.socher@copel.com \\ *****Eng. Florestal, Dr., Depto. de Ciências Florestais, UFPR - fgalvao@ufpr.br; roderjan@ufpr.br \\ Recebido para publicação: 23/05/2006 - Aceito para publicação: 21/07/2006
}

\begin{abstract}
Resumo
Este trabalho teve como objetivo caracterizar a composição e estrutura florística de um capão de floresta no município de Quatro Barras, inserido em Estepe do Primeiro Planalto Paranaense, relacionando relevo e solos. Com base na definição de compartimentos no ambiente, que considerou as formas e declividades das rampas e as características dos solos, foram instaladas parcelas para amostragem das árvores. As espécies responderam em diversidade e densidade às diferentes condições de drenagem dos Cambissolos e Gleissolos do capão. Podocarpus lambertii demonstrou elevada adaptabilidade a solos com diferentes regimes de saturação hídrica, enquanto Myrcia laruotteana apresentou relação estreita com solos saturados hidricamente. A compartimentação ambiental com base em geomorfologia e solos mostrou ser um quesito fundamental para a melhor compreensão da distribuição das espécies vegetais na paisagem.
\end{abstract}

Palavras-chave: Composição e estrutura florística; solos e relevo; Floresta Ombrófila Mista.

\section{Abstract}

Toposequence segmentation and phytosocial characterization of a copse from a Mixed Ombrophilous Forest. This work aim to characterize flora composition and structure of a copse, in Quatro Barras County, located in steppe area in first highland of Paraná, considering soil and topographic relief conditions. Based on the definition of compartments in the environment, that considered the forms and declivities of the slopes and the characteristics of soil, parcels for trees sampling had been installed. The species had answered in diversity and density to the different conditions of drainage of Cambissolos and Gleissolos of the copse. Podocarpus lambertii demonstrated high adaptability to soil with different moistures regimes, while Myrcia laruotteana presented narrow relation with water saturated soil. The environmental segmentation based on geomorphology and soil types showed to be fundamental aspect to better understand plants species distribution on the landscape.

Keywords: Flora composition and structure; soil and topographic relief; Mixed Ombrophyllous Forest.

\section{INTRODUÇÃO}

O Estado do Paraná apresentava, originalmente, uma cobertura vegetal predominantemente arbórea, ocupando cerca de 90,9\% de sua extensão territorial (IAP, 2003). Essa cobertura era constituída por distintas unidades fitogeográficas, como Floresta Ombrófila Densa, Floresta Ombrófila Mista e Floresta Estacional Semidecidual, além das formações não-florestais Estepes e Savanas (RODERJAN et al., 2003).

A Floresta Ombrófila Mista apresenta uma ampla distribuição pelo estado, tendo sua ocorrência registrada nos três planaltos paranaenses, entre as altitudes médias de $800 \mathrm{~m}$ a $1.200 \mathrm{~m}$ (RODERJAN et al., 2003). Do mesmo modo, nos citados planaltos, é reconhecida uma outra unidade fitogeográfica - a Estepe -, popularmente conhecida como campos de Guarapuava e de Palmas, no terceiro planalto, 
campos de Ponta Grossa, no segundo planalto, e campos de Curitiba, no primeiro. Essas formações são compostas por vegetação herbácea, com inclusões de agrupamentos arbóreos (independentemente de suas ocorrências se verificarem na beirada de rios ou não) exibindo uma florística extremamente rica, com conjunção de fatores indutores de delimitação geográfica ainda não determinada.

A discussão a respeito da cobertura original do Paraná acontece há muito tempo. Maack (1981) afirmava que "as estepes de gramíneas baixas e de arbustos constituíam a cobertura primária e mais antiga do Paraná", contrapondo-se a outros autores que afirmavam que os campos limpos tinham surgido como resultado da interferência humana, e que os cerrados seriam a vegetação clímax pela ação do fogo. Quanto aos campos de Curitiba, no entanto, Maack (op. cit.) concordava com Hertel (1969), que sustentava que estes provavelmente têm origem antrópica. A região apresenta todas as condições climáticas, edáficas e pedológicas para o desenvolvimento de florestas, no entanto, a formação predominante é constituída por herbáceas.

Nesse sentido, nenhum trabalho comenta, de forma conjunta, as ações antrópicas, passadas e recentes, aliadas às interferências climáticas e ainda, às características dos solos, principalmente quanto ao regime hídrico e sua distribuição na paisagem, considerados fatores fortemente restritivos ao avanço da floresta sobre os campos.

Associada à dizimação sofrida pela cobertura vegetacional original a partir da década de 40 do século passado, que alcançou níveis alarmantes de distribuição geográfica - $9 \%$ da cobertura original (SOS MATA ATLÂNTICA, 1998) -, a fragmentação e conseqüente insularização dos remanescentes induzem a uma menor funcionalidade ecológica dos ambientes, podendo levar à extinção "em cascata" de espécies que necessitam de áreas maiores para sobrevivência (HARRISON; BRUNA, 1999; WILSON, 1988).

Nas estepes, a pressão antrópica não foi diferente, restando 8,4\% da formação no estado (IAP, 2003). O componente herbáceo, devido à ocupação pelo homem, principalmente através dos sistemas produtivos, sofreu profundas alterações na sua composição, descaracterizando totalmente a florística original. Do mesmo modo, o componente florestal foi descaracterizado, principalmente pela queima e/ou derrubada generalizada e, em alguns casos, pela retirada seletiva de espécies com valor econômico ou para utilização dentro da propriedade rural.

Essa severa pressão antrópica configura um quadro bastante delicado, tendo em vista que ações de conservação e/ou recuperação desses ambientes incorrem, necessariamente, em estoque de informações técnicas específicas e, principalmente, integradas às demais áreas do conhecimento, como geologia, geomorfologia, pedologia e climatologia. Botrel et al. (2002) verificaram a influência do solo e da topografia sobre as variações da composição florística e da estrutura da comunidade arbórea-arbustiva de uma floresta em Minas Gerais. Infelizmente, sobre as estepes (especialmente as do primeiro planalto paranaense) não existem artigos científicos que relacionem a estrutura e a composição florística com os compartimentos geopedológicos. Essa relação é de extrema importância, pois embasa a estruturação dos ambientes, justificando, muitas vezes, a mudança na composição e na estrutura florística, assim como seu desenvolvimento. Da mesma forma, estudos sobre a diversidade e estrutura dos capões do primeiro planalto são escassos. Em Imaguire (1974) podem ser observadas a diversidade e a estrutura dessa tipologia, bem como a sua dinâmica funcional, porém não são mostradas as relações com os fatores geopedológicos existentes.

Este trabalho teve como objetivo caracterizar a composição e a estrutura florística de um capão de floresta inserido em Estepe do primeiro planalto paranaense, relacionando os dados fitossociológicos às características ambientais, com ênfase em solos e fatores geomórficos (declividade e forma de rampa).

\section{MATERIAIS E MÉTODOS}

A área estudada está localizada na Fazenda Experimental Canguiri, da Universidade Federal do Paraná, situada no município de Quatro Barras, primeiro planalto paranaense, pertencente à bacia hidrográfica do rio Iguaçu e sobreposta a grande diversidade litológica - Domínio Curitiba (BASEI et al.,1992). Especificamente, a bacia sedimentar onde se encontra a área de estudo é formada por argilitos, arcósios, depósitos rudáceos e caliche, de idade pliopleistocênica, depositados em grandes leques aluviais sob clima semi-árido (BIGARELLA et al., 1961; BIGARELLA; SALAMUNI, 1962). 
As formas de relevo presentes são dominantemente onduladas a suave onduladas, representando o modelamento de rampas desenvolvidas sobre a Formação Guabirotuba. O transecto de estudo está situado exclusivamente em posição de terço inferior da paisagem, em superfície próxima à cabeceira de vale assimétrico, composto por rampas côncava-convergentes suaves (toposseqüência 1) e convexaretilíneas (toposseqüência 2), conforme representado na Figura 1.

$\mathrm{Na}$ paisagem, predomina a unidade fitogeográfica da Estepe (RODERJAN et al., 2003), em clima, segundo a classificação de Koeppen, tipo $\mathrm{Cfb}$, mesotérmico úmido, com temperatura média do mês mais frio abaixo de $18{ }^{\circ} \mathrm{C}$, sem estação seca, com verão fresco e temperatura média do mês mais quente abaixo de $22{ }^{0} \mathrm{C}$.

De modo geral, a área da fazenda possui atividades agrossilvopastoris desenvolvidas em remanescentes naturais de estepes, entremeadas por capões próximos aos cursos d'água, de forma e dimensões variáveis.

A escolha do capão foi procedida após a interpretação de fotografias aéreas pancromáticas de 1985, pertencentes à COMEC (Coordenação da Região Metropolitana de Curitiba), em escala 1:8.000, seguida uma expedição a campo para verificar o estado de conservação da vegetação e, concomitantemente, os aspectos dessa cobertura relacionados às características de solos e sua distribuição na paisagem. Em momento posterior, foram realizadas novas incursões, buscando-se efetivar a compartimentação ambiental do capão selecionado, com ótica centrada em geomorfologia (forma de rampa e declividade) e pedologia (ênfase nos regimes hídricos). Os estudos de compartimentação da paisagem no capão foram sempre executados de forma toposseqüencial, em escala de ultradetalhe, buscando o seccionamento ambiental de uma única transeção, composta por duas toposseqüências (Figura 1).

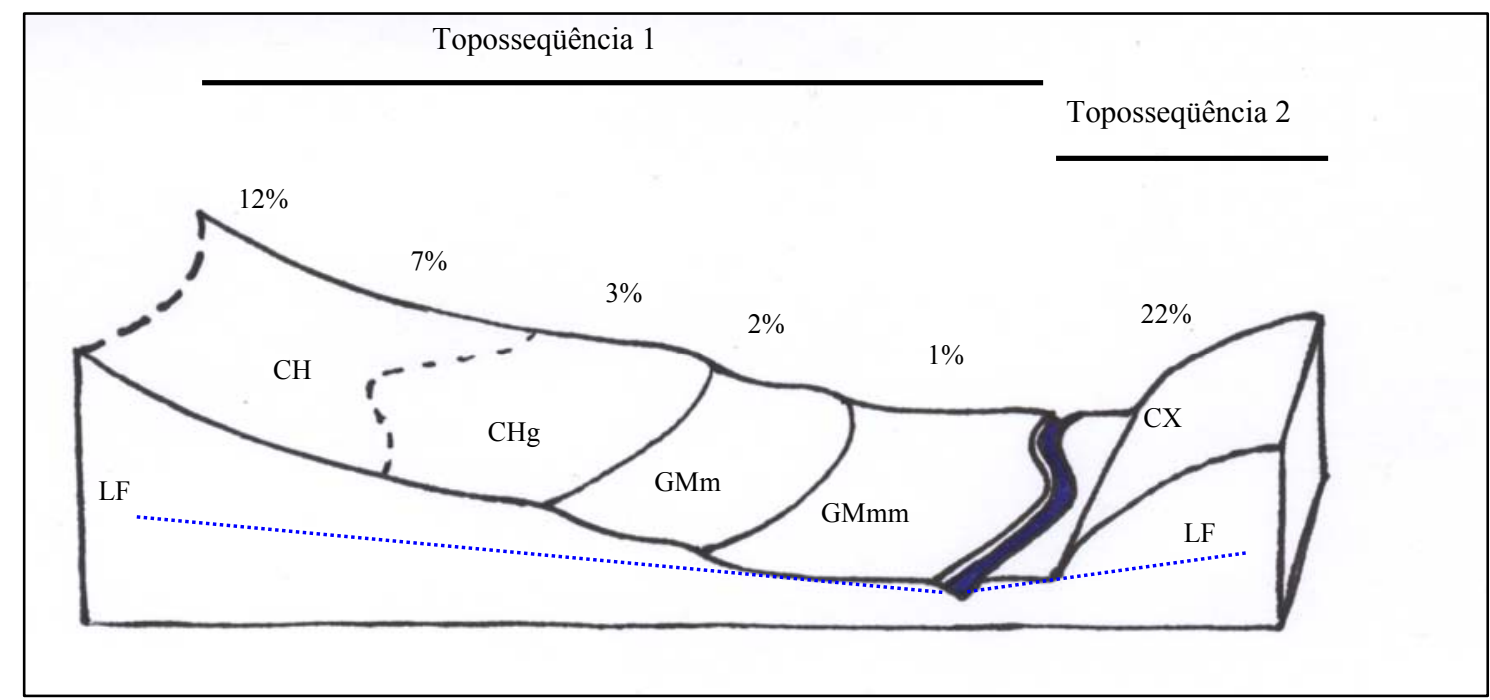

Figura 1. Distribuição das classes de solos, declividades e representação do lençol freático na área estudada. $\mathrm{CH}$ : Cambissolo Húmico distrófico típico; $\mathrm{CHg}$ : Cambissolo Húmico alumínico gleico; GMm: Gleissolo Melânico alumínico típico; GMmm: Gleissolo Melânico alumínico típico; CX: Cambissolo Háplico distrófico típico; LF: lençol freático.

Figure 1. Distribution of the soil classes; slopes and watertable depths on studied area. CH: Cambissolo Húmico distrófico típico; $\mathrm{CHg}$ : Cambissolo Húmico alumínico gleico; GMm: Gleissolo Melânico alumínico típico; GMmm: Gleissolo Melânico alumínico típico; CX: Cambissolo Háplico distrófico típico; LF: watertable.

Os solos coletados foram analisados nos laboratórios do Departamento de Solos da UFPR, de acordo com as normas estabelecidas em Embrapa (1997). A metodologia para levantamento de solos seguiu a padronização proposta em Lemos e Santos (1996), sendo que a classificação dos solos seguiu as normas estabelecidas em Embrapa (1999). Os fatores pedológicos preponderantes para o estabelecimento do seccionamento ambiental foram saturação por bases, profundidade efetiva e regime hídrico, nesse caso 
representado pelas drenagens. Cabe salientar que foram as características morfológicas como cor, presença de gleização e mosqueados, assim como graus de variegamento os maiores responsáveis pela compartimentação sob o ponto de vista pedológico. Contudo, para as partes mais abaciadas da paisagem, constituídas essencialmente por solos hidromórficos, foi também considerada a altura do lençol freático para separação dos ambientes. Foram estabelecidos cinco regimes de drenagens, a saber: muito mal drenados e mal drenados para os solos hidromórficos - Gleissolos; imperfeitamente drenados para semihidromórficos - Cambissolos gleicos; e moderadamente e bem drenados para os não-hidromórficos Cambissolos Húmicos e Háplicos típicos.

Dessa maneira, coerente à compartimentação proposta, empregou-se o método de parcelas múltiplas (MUELLER-DOMBOIS; ELLENBERG, 1974). Para amostrar a vegetação, foram instaladas 25 parcelas permanentes, cujas dimensões e localização ficaram condicionadas à homogeneidade pedológica e ao tamanho do capão. Desse modo, 20 parcelas possuem $50 \mathrm{~m}^{2}(5 \times 10 \mathrm{~m})$ e 5 parcelas ficaram com 25 $\mathrm{m}^{2}(2,5 \times 10 \mathrm{~m})$. Para a inclusão das espécies arbóreas em cada parcela, foi considerado o PAP (perímetro a $1,30 \mathrm{~m}$ de altura) mínimo de $15 \mathrm{~cm}$. Árvores com mais de um fuste, na altura citada, foram incluídas quando pelo menos uma delas apresentava o perímetro mínimo exigido. Os indivíduos foram numerados com placas de alumínio para identificação em posterior acompanhamento. As espécies e morfo-espécies foram coletadas e o material vegetal, em estágio reprodutivo ou não, foi herborizado para consulta no herbário do laboratório de Dendrologia do curso de Engenharia Florestal (EFC) da UFPR. A classificação foi baseada em Cronquist (1988), e os nomes das espécies foram conferidos em Mobot (2004). Teve-se o cuidado de evitar a materialização das parcelas em áreas onde existiam clareiras ou mesmo em que a cobertura vegetal fosse composta por estágios sucessionais em fases de desenvolvimento heterogêneo.

A estrutura da comunidade arbóreo-arbustiva foi analisada a partir do cálculo dos parâmetros fitossociológicos descritos em Mueller-Dombois; Ellenberg (1974) e calculados com auxílio do programa FITOPAC, versão 1,0 (SHEPHERD, 1988). Sua diversidade foi analisada utilizando-se o índice de Shannon (H') (MAGURRAN, 1988).

\section{RESULTADOS E DISCUSSÃO}

A toposseqüência 1, sobre formas suaves que conferem convergência hídrica, em sua porção superior é composta por Cambissolos Húmicos $\mathrm{Tb}$ distróficos típicos e lépticos textura argilosa relevo ondulado (12\%) substrato argilitos (Tabela 1), sendo a baixa saturação por bases característica comum para os solos de encosta da região (EMBRAPA, 1984). O horizonte A, com espessuras em torno de 40 a $50 \mathrm{~cm}$, manifesta os elevados teores de matéria orgânica através da cor bruno-muito-escuro, a qual contrasta fortemente com as cores bruno a bruno-amarelado-escuro do horizonte Bi (Tabela 1). As cores do horizonte subsuperficial em profundidades próximas a $1 \mathrm{~m}$ refletem a classe de drenagem bem a moderadamente drenado. No centro da toposseqüência, em relevo suave ondulado, encontra-se uma classe de solo com baixa saturação por bases e elevados teores de alumínio trocável, sendo classificado como Cambissolo Húmico Tb alumínico gleico textura argilosa. O horizonte superficial de cor preta, sobrejacente ao horizonte $\mathrm{Bi}$, de cor bruno-amarelada, com indícios de mosqueamentos em torno de 75 a $100 \mathrm{~cm}$, reflete as restrições à drenagem - imperfeitamente drenado. O caráter gleico evidencia a presença de indícios de gleização entre as profundidades de 50 e $100 \mathrm{~cm}$. No final da toposseqüência, em planície aluvionar, tem-se Gleissolos Melânicos alumínicos típicos textura argilosa relevo plano.

A planície do rio Iguaçu (RAUEN et al., 1994), assim como as planícies de seus afluentes (BUFREM, 1997; BARDDAL, 2002), apresentam solos com baixa saturação por bases, comumente com caráter alumínico. Gleissolos em posição pouco mais elevada em relação ao curso d'água, o que possibilita altura do lençol freático em torno de $30 \mathrm{~cm}$, apresentam regime mal drenado, enquanto aqueles identificados no mesmo nível que o córrego apresentam lençol praticamente na superfície e regime muito mal drenado. As fortes condições de redução impostas pelo freático traduzem-se nas cores cinza-escuro a preto da superfície e cinza-escuro com mosqueados no horizonte $\mathrm{Cg}$. Assim como os Cambissolos, têm baixa saturação por bases no complexo de troca e elevados teores de alumínio trocável, sendo, por esse motivo, segundo Embrapa (1999), classificados como Gleissolos Melânicos alumínicos típicos.

A toposseqüência 2, na encosta, é composta apenas por Cambissolo Háplico Tb distrófico típico A proeminente textura argilosa relevo forte ondulado substrato argilitos. O horizonte A apresenta espessura entre 30 e $40 \mathrm{~cm}$, cor bruno-escuro sobre horizonte subsuperficial bruno-forte a bruno- 
amarelado-escuro. No final dessa toposseqüência, verifica-se uma mudança de relevo mais abrupta para a planície, devido à maior proximidade do córrego dessa encosta.

Tabela 1. Resultados analíticos granulométricos e químicos dos solos nos compartimentos estudados.

Table 1. Data of soil particle distribution and chemical characteristics on the studied compartments.

\begin{tabular}{|c|c|c|c|c|c|c|c|c|c|c|}
\hline \multirow{2}{*}{$\begin{array}{l}\text { Classe } \\
\text { de solo }\end{array}$} & \multirow{2}{*}{ Horizonte } & \multirow{2}{*}{$\frac{\mathrm{pH}}{\left(\mathrm{CaCl}_{2}\right)}$} & $\mathbf{C}$ & Al & $\mathbf{H}+\mathbf{A l}$ & $\mathbf{T}$ & V & Areia & Silte & Argila \\
\hline & & & \multicolumn{4}{|c|}{$\left(\mathrm{cmol}_{\mathrm{c}} / \mathrm{dm}^{3}\right)$} & \multicolumn{4}{|c|}{$(\%)$} \\
\hline $\mathrm{CH}$ & $\mathrm{A}$ & 4,3 & 49,2 & 2,5 & 12,1 & 15,9 & 24 & 30 & 34 & 36 \\
\hline $\mathrm{CH}$ & $\mathrm{Bi}$ & 4,4 & 38,4 & 3.5 & 15,8 & 20,7 & 23 & 20 & 40 & 40 \\
\hline $\mathrm{CHg}$ & A & 4,4 & 54,6 & 1,1 & 14,4 & 24,6 & 41 & 24 & 30 & 46 \\
\hline $\mathrm{CHg}$ & Big & 4,1 & 11,8 & 6,0 & 16,3 & 18,2 & 10 & 26 & 26 & 48 \\
\hline GMm & $\mathrm{A}$ & 6,4 & 58,2 & 2,8 & 17,2 & 26,7 & 35 & 25 & 40 & 35 \\
\hline GMm & $\mathrm{Cg}$ & 4,0 & 13,6 & 6,2 & 16,3 & 20,6 & 20 & 24 & 34 & 42 \\
\hline GMmm & $\mathrm{A}$ & 6,9 & 64,6 & 5,1 & 20,6 & 23,1 & 11 & 21 & 42 & 37 \\
\hline GMmm & $\mathrm{Cg}$ & 4,2 & 16,0 & 5,5 & 15,2 & 16,6 & 8 & 22 & 42 & 36 \\
\hline $\mathrm{CX}$ & $\mathrm{A}$ & 5,0 & 50,4 & 0,7 & 12,1 & 21,8 & 44 & 26 & 36 & 38 \\
\hline $\mathrm{CX}$ & $\mathrm{Bi}$ & 4,8 & 21,4 & 3,8 & 12,1 & 14,1 & 14 & 20 & 30 & 50 \\
\hline
\end{tabular}

CH: Cambissolo Húmico distrófico típico; $\mathrm{CHg}$ : Cambissolo Húmico alumínico gleico; GMm: Gleissolo Melânico alumínico típico; GMmm: Gleissolo Melânico alumínico típico; CX: Cambissolo Háplico distrófico típico; C: carbono; Al: alumínio; H: hidrogênio; T: Capacidade de troca catiônica; V: saturação por bases.

Considerando o tamanho total da área amostral $\left(1.125 \mathrm{~m}^{2}\right)$, pode-se afirmar que a cobertura vegetal arbórea do capão apresenta ampla diversidade, sendo a florística e a estrutura representantes de dois padrões fisionômicos distintos, com espécies típicas de ambientes bem e mal drenados. As 51 espécies pertencem a 27 famílias e ocorrem de modo semelhante sobre solos com diferentes regimes hídricos, sugerindo alteração antrópica no passado, uma vez que era esperado um número maior em Cambissolo Húmico.

A menor densidade absoluta, menor número de famílias e de espécies arbóreas e menor índice de Shannon em Cambissolo Húmico distrófico típico - $\mathrm{CH}$, da toposseqüência 1, contraria as expectativas, pois esse solo, típico da região, não apresenta restrição alguma a pluralidade florística (Tabela 2). O diâmetro máximo, bem como a altura máxima dos indivíduos que compõem a população nesse compartimento, também indica a ausência de elementos de grande porte, situação esperada para solos argilosos, consistentes, profundos, pertencentes à classe de drenagem bem/moderadamente drenado.

Tabela 2. Parâmetros fitossociológicos calculados para os diferentes compartimentos das toposseqüências 1 e 2 .

Table 2. Calculated phytossociological parameters for different compartments on 1 and 2 landscapes.

\begin{tabular}{|c|c|c|c|c|c|c|c|c|c|}
\hline $\begin{array}{l}\text { Classe } \\
\text { de solo }\end{array}$ & $\begin{array}{c}\text { Espécies } \\
\left(n^{0}\right)\end{array}$ & $\begin{array}{c}\text { Famílias } \\
\quad\left(\mathbf{n}^{\mathbf{0}}\right)\end{array}$ & $\begin{array}{l}\text { Shannon } \\
\text { (nats/indiv) }\end{array}$ & $\begin{array}{c}\text { DA } \\
\left(n^{\circ} \text { ind } / h a\right)\end{array}$ & $\underset{\left(\mathrm{m}^{2} / \mathrm{ha}\right)}{\operatorname{DoA}}$ & $\begin{array}{l}\text { Diâm. } \\
\text { máx. } \\
\text { (cm) }\end{array}$ & $\begin{array}{l}\text { Diâm. } \\
\text { méd. } \\
\text { (cm) }\end{array}$ & $\begin{array}{l}\text { Alt. } \\
\text { máx. } \\
\text { (m) }\end{array}$ & $\begin{array}{l}\text { Alt. } \\
\text { méd. } \\
\text { (m) }\end{array}$ \\
\hline $\mathrm{CH}$ & 12 & 11 & 2,213 & 2320 & 46,33 & 39,50 & 13,57 & 13,00 & 8,62 \\
\hline $\mathrm{CHg}$ & 22 & 14 & 2,512 & 3400 & 50,37 & 34,5 & 12,47 & 12,00 & 8,05 \\
\hline GMm & 15 & 12 & 2,431 & 3920 & 52,84 & 26,6 & 11,85 & 11,00 & 6,29 \\
\hline GMmm & 18 & 13 & 2,433 & 2520 & 31,51 & 31,90 & 11,04 & 11,00 & 6,17 \\
\hline $\mathrm{CX}$ & 29 & 14 & 3,016 & 3280 & 56,51 & 60,8 & 11,23 & 24,00 & 8,51 \\
\hline
\end{tabular}

CH: Cambissolo Húmico distrófico típico (bem/moderadamente drenado); $\mathrm{CHg:} \mathrm{Cambissolo} \mathrm{Húmico} \mathrm{alumínico} \mathrm{gleico}$ (imperfeitamente drenado); GMm: Gleissolo Melânico alumínico típico (mal drenado); GMmm: Gleissolo Melânico alumínico típico (muito mal drenado); CX: Cambissolo Háplico distrófico típico (bem drenado); DA: Densidade Absoluta; DoA: Dominância Absoluta.

As espécies Podocarpus lambertii, Lithraea brasiliensis e Eugenia pluriflora apresentaram os maiores percentuais de importância, assim como no compartimento imediatamente abaixo na toposseqüência - Cambissolo gleico (Tabela 3). Isso indica que as três espécies estão bem adaptadas aos dois regimes hídricos prevalecentes de solos de encosta - não-hidromórficos e semi-hidromórficos. $\mathrm{O}$ 
maior valor de importância de Podocarpus lambertii nesse compartimento deve-se também à ausência de Araucaria angustifolia, cujo valor de importância, nas condições originais da Floresta Ombrófila Mista, se sobrepõe às demais espécies. A ocorrência de Podocarpus lambertii em ambientes constituídos por Gleissolos mal e muito mal drenados demonstra sua elevada adaptabilidade a solos com diferentes regimes de saturação hídrica, e sua maior dominância nesse compartimento e no seguinte reflete o bom desenvolvimento da espécie em solos com regime hídrico não-saturado.

Tabela 3. Parâmetros fitossociológicos das espécies com os maiores valores de importância nos diferentes compartimentos estudados.

Table 3. Phytossociological parameters of species with the greatest importance value on different studied compartments.

\begin{tabular}{|c|c|c|c|c|c|c|c|c|c|}
\hline $\begin{array}{c}\text { Solo } \\
\text { drenagem }\end{array}$ & Espécie & $\mathbf{N}$ & $\begin{array}{c}\text { DoA } \\
\left(\mathrm{m}^{2} / \mathrm{ha}\right)\end{array}$ & $\begin{array}{l}\text { DoR } \\
(\%)\end{array}$ & $\begin{array}{c}\text { DA } \\
\text { (N/ha) }\end{array}$ & $\begin{array}{l}\text { DR } \\
(\%)\end{array}$ & $\begin{array}{l}\text { FA } \\
(\%)\end{array}$ & $\begin{array}{l}\text { FR } \\
(\%)\end{array}$ & VI \\
\hline & Podocarpus lambertii Klot. ex Endl. & 15 & 22,3 & 48,2 & 600 & 25,8 & 100 & 14,7 & 29,6 \\
\hline Cambissolo & Lithraea brasiliensis Marchand & 8 & 7,9 & 17,1 & 320 & 13,7 & 100 & 14,7 & 15,2 \\
\hline Húmico & Eugenia pluriflora DC. & 8 & 2,1 & 4,6 & 320 & 13,7 & 80 & 11,7 & 10,0 \\
\hline $\mathrm{bem} / \mathrm{mod}$. & Alibertia concolor (C.) K. Schum. & 5 & 0,7 & 1,5 & 200 & 8,6 & 80 & 11,7 & 7,3 \\
\hline \multirow[t]{2}{*}{ Drenado } & Ocotea pulchella (Ness) Mez & 4 & 1,6 & 3.5 & 160 & 6,9 & 60 & 8,8 & 6,4 \\
\hline & Drimys brasiliensis Miers & 2 & 4,1 & 8,8 & 80 & 3,4 & 20 & 2,9 & 5,0 \\
\hline \multirow{6}{*}{$\begin{array}{l}\text { Cambissolo } \\
\text { Gleico } \\
\text { imperfeitamente } \\
\text { drenado }\end{array}$} & Podocarpus lambertii Klot. ex Endl. & 26 & 29,9 & 59,5 & 1.040 & 30,5 & 100 & 11,1 & 33,7 \\
\hline & Lithraea brasiliensis Marchand & 9 & 8,1 & 16,1 & 360 & 10,5 & 100 & 11,1 & 12,6 \\
\hline & Eugenia pluriflora DC. & 7 & 0,9 & 1,8 & 280 & 8,2 & 80 & 8,8 & 6,3 \\
\hline & Capsicodendron dinisii (S.) Occhioni & 4 & 1,7 & 3,4 & 160 & 4,7 & 60 & 6,6 & 4,9 \\
\hline & Ilex theezans Mart. & 5 & 1,7 & 3,3 & 200 & 5,8 & 40 & 4,4 & 4,5 \\
\hline & Ocotea pulchella (Ness) Mez & 3 & 0,4 & 0,8 & 120 & 3,5 & 60 & 6,6 & 3,6 \\
\hline \multirow{6}{*}{$\begin{array}{l}\text { Gleissolo } \\
\text { Melânico } \\
\text { mal drenado }\end{array}$} & Myrcia laruotteana Cambess. & 12 & 16,8 & 31,2 & 960 & 23,5 & 100 & 14,2 & 23,0 \\
\hline & Lithraea brasiliensis Marchand & 4 & 9,4 & 17,5 & 320 & 7,8 & 60 & 8,5 & 11,3 \\
\hline & Podocarpus lambertii Klot. ex Endl. & 6 & 5,3 & 9,9 & 480 & 11,7 & 80 & 11,4 & 11,0 \\
\hline & Schinus terebinthifolius Raddi & 5 & 2,5 & 4,6 & 400 & 9,8 & 60 & 8,5 & 7,6 \\
\hline & Sebastiania commersoniana (B.) Sm. e Downs & 2 & 5,2 & 9 & 160 & 3,9 & 40 & 5,7 & 6,4 \\
\hline & Ilex theezans Mart. & 3 & 3,3 & 6,2 & 240 & 5,8 & 40 & 5,7 & 5,9 \\
\hline \multirow{6}{*}{$\begin{array}{l}\text { Gleissolo } \\
\text { Melânico } \\
\text { muito mal } \\
\text { drenado }\end{array}$} & Myrcia laruotteana Cambess. & 17 & 12,5 & 39,8 & 680 & 26,9 & 100 & 13,1 & 26,6 \\
\hline & Myrsine umbellata Mart. & 11 & 1,9 & 6,2 & 640 & 17,4 & 80 & 10,5 & 11,4 \\
\hline & Ilex theezans Mart. & 6 & 3,1 & 9,9 & 240 & 9,5 & 80 & 10,5 & 10,0 \\
\hline & Psidium cattleyanum Sabine & 5 & 1,2 & 3,9 & 200 & 7,9 & 60 & 7,8 & 6,5 \\
\hline & Xylosma ciliatifolia (Clos) Eichler & 2 & 3,2 & 10,4 & 80 & 3,1 & 40 & 5,2 & 6,2 \\
\hline & Podocarpus lambertii Klot. ex Endl. & 3 & 0,9 & 2,9 & 120 & 4,7 & 60 & 7,8 & 5,1 \\
\hline \multirow{6}{*}{$\begin{array}{l}\text { Cambissolo } \\
\text { Háplico } \\
\text { bem drenado }\end{array}$} & Araucaria angustifolia (B.) Kuntze & 2 & 21,9 & 38,8 & 80 & 2,4 & 40 & 3,4 & 14,9 \\
\hline & Myrcia rostrata DC. & 11 & 4,9 & 8,7 & 440 & 13,4 & 100 & 8,6 & 10,2 \\
\hline & Podocarpus lambertii Klot. ex Endl. & 6 & 5,0 & 8,9 & 240 & 7,3 & 80 & 6,9 & 7,7 \\
\hline & Eugenia pluriflora DC. & 6 & 0,8 & 1,4 & 240 & 7,3 & 100 & 8,6 & 5,7 \\
\hline & Psychotria sp. & 5 & 0,9 & 1,7 & 200 & 6,1 & 80 & 6,9 & 4,9 \\
\hline & Ocotea corymbosa (Meisn.) Mez & 3 & 4,0 & 7,1 & 120 & 3,6 & 40 & 3,4 & 7,7 \\
\hline
\end{tabular}

N: Número de indivíduos; DA: densidade absoluta; FA: freqüência absoluta; DoA: dominância absoluta; DR: densidade relativa; FR: freqüência relativa; DoR: dominância relativa; VI: valor de importância.

Em Cambissolo Húmico alumínico gleico - $\mathrm{CHg}$, apesar das condições de semi-hidromorfia identificadas no solo que compõe esse compartimento, é possível verificar, através das tabelas 2 e 3 , a maior densidade absoluta, com praticamente o dobro de espécies do compartimento anterior. Essa constatação contraria a tendência da região, de que quanto maior o regime de saturação hídrica menor a diversidade florística, ratificando a hipótese de que no compartimento anterior tenha ocorrido a retirada seletiva de espécies. O mesmo parece ter ocorrido nesse compartimento, onde a densidade absoluta é menor do que a do compartimento constituído por Gleissolo na classe de drenagem mal drenado.

Em Gleissolo Melânico alumínico típico - GMm, a presença da Myrcia laruotteana como a espécie mais importante (Tabela 3), ratificada pela sua importância no compartimento seguinte, evoca afinidade da espécie a solos com regime temporário de saturação hídrica plena, como já detectado por Bufrem (1997). Vale ressaltar o hábito freqüente de perfilhamento nos indivíduos dessa espécie, o que pode ser uma estratégia da planta para manter estabilidade em períodos de maior encharcamento, quando o solo assume características semifluidais, propiciando menores condições de sustentação para indivíduos arbóreos. A baixa diversidade nesse compartimento, ratificada pelo índice de Shannon, é coerente a solos 
hidromórficos, dada a seletividade imposta por esse tipo de regime hídrico (Tabela 2). Por outro lado, os maiores índices de densidade e dominância absolutas indicam o melhor estado de conservação da vegetação, condição essa relacionada à dificuldade de acesso pelo encharcamento do solo.

Sebastiania commersoniana é típica de ambientes de planície (BUFREM, 1997; OLIVEIRA, 2001; SOUZA, 2001; BARDDAL, 2002; FUPEF, 2003), mas apresentou pequeno número de indivíduos (Tabela 3). Os baixos índices lumínicos nesse ambiente podem estar comprometendo a presença da referida espécie, uma vez que se trata de planta pioneira. Sua pequena ocorrência também deve estar atrelada aos elevados teores de matéria orgânica,próximos ao piso mínimo para enquadramento em horizonte hístico, o qual confere baixa capacidade de sustentação para indivíduos arbóreos (Tabela 1).

Em Gleissolo Melânico alumínico típico - GMmm, a menor densidade absoluta, seguida pela menor dominância em relação ao compartimento anterior, é reflexo direto do regime hídrico de saturação - muito mal drenado (Tabela 2). O encharcamento é resultante da baixa permeabilidade do solo, posição de fundo de vale, e forma de escorrimento hídrico difuso (fluxo não canalizado) em períodos de maior precipitação. A presença da água na superfície do solo também justifica o baixo número de espécies, além da altura dos indivíduos, que diminui ao longo da toposseqüência 1.

Em Cambissolo Háplico distrófico típico - CX da toposseqüência dois, Araucaria angustifolia destaca-se fortemente pelo porte, apresentando alta porcentagem de importância devido a sua dominância. O índice de Shannon é o mais elevado de todo o transecto, caracterizando a maior diversidade florística e ratificando a grande permissividade para a ingressão da floresta em solos com boa profundidade efetiva. Guardadas as proporcionalidades para as diferentes classes diamétricas, a densidade absoluta desse compartimento é considerada padrão dentro da tipologia Floresta Ombrófila Mista (LONGHI, 1980; GALVÃO et al.,1989), sendo bem superior à encontrada no Cambissolo Húmico distrófico típico, solo similar, caracterizando o melhor estado de conservação, inclusive com a presença de Araucaria angustifolia.

A presença da Ocotea corymbosa na quinta posição, condição similar verificada com Ocotea pulchella em Cambissolo Húmico bem e imperfeitamente drenado, atesta a maior adaptabilidade das lauráceas aos solos não-hidromórficos.

\section{CONCLUSÕES}

A compartimentação ambiental, com base em geomorfologia e solos, é quesito fundamental para a melhor compreensão da distribuição das espécies vegetais na paisagem.

A convergência dos fluxos hídricos, condicionada pelas formas de rampas, justifica os regimes hídricos dos solos e influencia diretamente a diversidade florística.

\section{AGRADECIMENTOS} dos solos.

A Renato Antonio Dedecek, pesquisador da Embrapa Florestas, pela discussão do regime hídrico

\section{REFERÊNCIAS}

BARDDAL, M. L. Aspectos florísticos e fitossociológicos do componente arbóreo-arbustivo de uma floresta ombrófila mista aluvial - Araucária, PR. 2002. 90f. Dissertação (Mestrado) - Universidade Federal do Paraná, Curitiba.

BASEI, M. A. S.; SIGA JÚNIOR., O.; MACHIAVELLI, A. Evolução tectônica dos terrenos entre os cinturões Ribeira e Dom Feliciano (PR-SC). Revista Brasileira de Geociências, v.22, p.212-227, 1992.

BIGAREllA, J. J.; SAlAMUNI, J. R. Caracteres texturais dos sedimentos da Bacia de Curitiba. Boletim da UFPR, v.7. p.1-164, 1962.

BIGARELlA, J. J.; SALAMUNI, J.; AB'SABER, A. N. Origem e ambiente de deposição da Bacia de Curitiba. Boletim Paranaense de Geografia, v. 4/5. p.71-81, 1961. 
BOTREL, R. T.; OLIVEIRA FILHO, A. T.; RODRIGUES, L. A.; CURI, N. Influência do solo e topografia sobre as variações da composição florística e estrutura da comunidade arbórea-arbustiva de uma floresta estacional semidecidual em Ingaí, MG. Revista Brasileira de Botânica, v. 25, p.195-213, 2002.

BUFREM, A. M. Caracterização fitossociológica de um remanescente da floresta ripária do rio Pequeno, São José dos Pinhais - PR. 1997. 87f. Dissertação (Mestrado) - Universidade Federal do Paraná, Curitiba.

CRONQUIST, A. The evolution and classification of flowering plants. New York: The New York Botanical Garden. 1988. 555p.

EMBRAPA. Serviço Nacional de Levantamento e Conservação de Solos. Levantamento de Reconhecimento dos Solos do Estado do Paraná. Boletim Técnico, Curitiba, nº 57, 788p. 1984.

EMBRAPA. Centro Nacional de Pesquisa de Solos (Rio de Janeiro, RJ). Manual de métodos de análise de solo. Rio de Janeiro: Embrapa Solos, 1997. 212p.

EMBRAPA. Centro Nacional de Pesquisa de Solos (Rio de Janeiro, RJ). Sistema Brasileiro de Classificação de Solos. Rio de Janeiro: Embrapa Solos, 1999. 412p.

FUPEF. Diagnóstico da Cobertura Vegetal da Área Proposta para a Construção da PCH São Jerônimo e do Contexto Vegetacional do seu Entorno. Curitiba: Brascan - Fupef. 2003. 83p.

GALVÃO, F.; KUNIYOSHI, Y. S.; RODERJAN, C. V. Levantamento Fitossociológico das principais associações arbóreas da Floresta Nacional de Irati - PR. Revista Floresta, Curitiba, v. 19, p.30-49, 1989.

HARRISON, S.; BRUNA, E. Habitat Fragmentation on Large-scale Conservation: what do we know for sure?. Ecography, v.22, p.225-232, 1999.

HERTEL, R. Aspectos interessantes da vegetação do Paraná. In: História do Paraná - $2^{\circ}$ volume. Curitiba: Grafipar, 1969.

IAP, Instituto Ambiental do Paraná. Portal do Meio Ambiente. Disponível em: $<$ http://www.pr.gov.br/sema> . Acesso em: 22 nov. 2003.

IMAGUIRE, N. Contribuição ao estudo da flora da Fazenda Experimental do setor de Ciências Agrárias sob o ponto de vista de botânica básica e aplicada aos problemas do meio rural. 1974. Curitiba: UFPR. 120p.

LEMOS, R.C. de; SANTOS, R.D. Manual de descrição e coleta de solo no campo. 3.ed. Campinas: Sociedade Brasileira de Ciência do Solo, 1996. 83p.

LONGHI, S.J.A. Estrutura de uma floresta natural de Araucaria angustifolia (Bert.) O. Ktze, no Sul do Brasil. 1980. 198f. Dissertação (Mestrado) - Universidade Federal do Paraná, Curitiba.

MAACK, R. Geografia Física do estado do Paraná. Rio de Janeiro: J. Olympio, 1981. 450p.

MAGURRAN, A.E. Ecological diversity and its measurement. New Jersey: Princeton University Press, 1988. 179 p.

MOBOT, Missouri Botanical Garden's, 2003. Disponível em: http://www.mobot.mobot.org/W3T/Search/vast.html > Acesso em: 3 nov. 2003.

MUELlER-DOMBOIS, D.; ELLENBERG, H. Aims and methods of vegetation ecology. New York: John Wiley e Sons, 1974. 547p.

OLIVEIRA, E.A. Caracterização florística, fitossociológica e pedológica de um trecho da floresta ripário dos Campos Gerais do Paraná. 2001. 106f. Dissertação (Mestrado) - Universidade Federal do Paraná, Curitiba.

RAUEN, M. J.; FASOlO, P. J.; PÖTTER, R. O.; CARDOSO, A.; CARVALHO, A. P.; HOCHMULLER, D. P.; CURCIO, G. R.; RACHWAL, M. F. G. Levantamento semidetalhado dos solos. In: HENKLAIN, J. C. (Coord.). Potencial de uso agrícola das áreas de várzea do Estado do Paraná; Bacias Hidrográficas dos rios das Cinzas e Laranjinha, Iapó, Iguaçu, Piquiri, Pirapó, Tibagi e Litoral. Boletim técnico IAPAR, Londrina, v.2., n.24, p.5-59.1994. 
RODERJAN, C. V.; GALVÃO, F.; KUNIYOSHI, Y. S.; HATSCHBACK, G. As unidades fitogeográficas do Estado do Paraná. Ciência e Ambiente, Santa Maria, v.24, p.75-92, 2003.

SHEPHERD, G. J. Fitopac 1: versão preliminar - software computacional e manual do usuário. Campinas, Depto. de Botânica da UNICAMP, 1988.

S.O.S MATA ATLÂNTICA, FUNDAÇÃO. Atlas da Evolução dos remanescentes florestais associados no Domínio da Mata Atlântica no período de 1990-1995. São Paulo: Fundação SOS Mata Atlântica, 1998. 54p.

SOUZA, M. K. F. Florística e fitossociologia do estrato arbóreo-arbustivo de diferentes compartimentos em ambiente fluvial no município de Jaguariaíva - PR. 2001. 108f. Dissertação (Mestrado) - Universidade Federal do Paraná, Curitiba.

WILSON, E. O. Biodiversidade. Rio de Janeiro: Ed. Nova Fronteira, 1988. 657p. 